\title{
Arsenic remediation through magnetite based in situ immobilization
}

\author{
J. Sun ${ }^{1}$, B.C. Bostick ${ }^{2}$, S.N. Chillrud ${ }^{2}$, B.J. Mailloux ${ }^{3} \&$ H. Prommer ${ }^{4}$ \\ ${ }^{1}$ University of Western Australia \& CSIRO Land and Water, Perth, WA, Australia \\ ${ }^{2}$ Barnard College and Lamont-Doherty Earth Observatory, Columbia University, New York, NY, USA \\ ${ }^{3}$ Department of Environmental Sciences, Barnard College, New York, NY, USA \\ ${ }^{4}$ University of Western Australia \& CSIRO Land and Water, Perth, WA, Australia
}

\begin{abstract}
The remediation of arsenic-contaminated aquifers is a formidable challenge to achieve, in part because geochemical conditions often do not favor the stabilization of arsenic within the solid phase. A promising remedial approach involves stimulating iron mineral transformations that immobilize arsenic through sorption or precipitation. Despite intense research, the current immobilization methods are still often ineffective, in part because many iron minerals are susceptible to redox gradients common in subsurface environments. We have been conducting a series of studies to illustrate the potential of nanoparticulate magnetite $\left(\mathrm{Fe}_{3} \mathrm{O}_{4}\right)$ to sequester arsenic. Magnetite is stable under most redox conditions in aquifers, and able to co-precipitate and adsorb arsenic. Here, we present results from microcosm and column experiments using sediments and groundwater from U.S. Superfund sites, and from reactive transport modelling. All these results demonstrate that in situ formation of nanoparticulate magnetite can be achieved by the combination of nitrate and ferrous iron, and that it should be feasible to produce an in situ reactive filter by such nitrate-iron(II) co-injection and immobilize arsenic in contaminated aquifers.
\end{abstract}

\section{INTRODUCTION}

Groundwater arsenic contamination is a global public health problem and also a concern at hundreds of U.S. Superfund sites (ATSDR, 2015). Mitigating groundwater arsenic contamination is urgently required, however, has proven difficult. One attractive remedial option is in situ immobilization, which stimulates changes in the chemical speciation of arsenic and/or other elements within the aquifer to adsorb and/or precipitate arsenic. Magnetite $\left(\mathrm{Fe}_{3} \mathrm{O}_{4}\right)$ can potentially be an advantageous host-mineral for arsenic immobilization in that it is stable under a wide range of aquifer conditions including both oxic and iron(III)-reducing environments. We, therefore, have been investigating methods to stimulate in situ magnetite formation, and evaluating the effect of magnetite formation on immobilizing arsenic, through both laboratory experiments and numerical modelling.

\section{MATERIALS AND METHODS}

\subsection{Microcosm and column experiments}

A series of microcosms were performed by mixing sediments and groundwater from the Vineland Chemical Company Superfund site, and then amended as: (i) control, (ii) sulfate-lactate treatment, (iii) nitrateonly treatment and (iv) nitrate-iron(II) treatment. To test the stability of the neoformed minerals, lactate was added in nitrate-only and nitrate-iron(II) microcosms on day 10 to stimulate microbial reduction. The microcosms were incubated semi-anaerobically in sealed bottles. The duration was 38 days, during which solution composition and mineralogical transformations were determined.

To conduct column experiment, sediments from the Dover Municipal Landfill Superfund site were used. Four experimental stages were designed. Stage I used artificial groundwater (A-GW) with lactate and arsenic (III), to equilibrate the sediments and mimic landfill conditions. Stage II used A-GW with lactate, arsenic (III), iron (II) and nitrate, to produce minerals and test if they could immobilize arsenic. Stage III used A-GW with elevated concentration of lactate, to examine the stability of the neoformed minerals. Stage IV used the same composition with Stage I, to return to landfill condition and test if the neoformed minerals could immobilize additional transported arsenic. The influents were purged with $\mathrm{N}_{2}(\mathrm{~g})$ and injected at 2 pore volumes $(\mathrm{PVs})$ day $^{-1}$. The duration was 4 months, during which solution composition and mineralogical transformations were determined.

\subsection{Reactive transport modeling}

The initial geochemical and flow condition of the Dover columns were reconstructed using PHREEQC and MODFLOW, which formed the basis for the subsequent simulations with the reactive transport code PHT3D (Prommer et al., 2003). The reactive transport model contained two distinct sets of reactions: one 


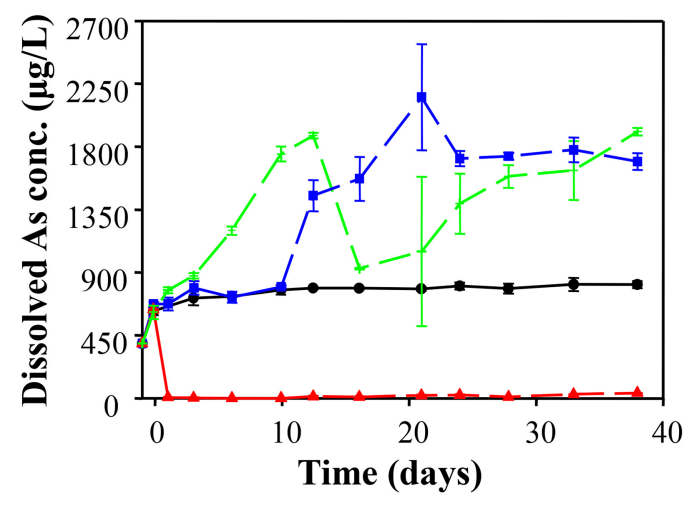

Figure 1. Dissolved arsenic concentrations in the microcosms. The dashed lines indicate the portion where lactate was present. Modified from Sun et al. (2016a and 2016b).

set focused on mineral (trans)formation, whereas the other focused on the effect of the mineralogical changes on surface sites and associated surface species. Except for the few reactions with no known rate constants, most initial parameters were from literatures. A calibration procedure was then employed to refine the parameters, to match up simulation with observation temporally and spatially. Based on the calibrated parameters, 2D simulations was then conducted, to predict the efficiency of the nitrate-iron(II) strategy on immobilizing arsenic at field-scale.

\section{RESULTS AND DISCUSSION}

In the nitrate-iron(II) microcosms, effective arsenic removal from solution was observed, even under sustained microbial reduction (Fig. 1). The enhanced arsenic retention was mainly attributed to coprecipitation within magnetite and adsorption on a mixture of magnetite and ferrihydrite. Ferrihydrite was unstable under reducing conditions, while magnetite and the associated arsenic were stable. Arsenic solubility increased in the other microcosms including those designed to stimulate sulfate reduction.

In the column experiment, prior to nitrate-iron(II) addition, arsenic was not effectively retained within the sediments (Fig. 2). Following nitrate-iron(II) addition, magnetite and ferrihydrite formed in the columns, which rapidly decreased effluent arsenic concentrations to $<10 \mu \mathrm{g} \mathrm{L}^{-1}$. This magnetite persisted in the columns even as conditions became reducing, whereas ferrihydrite was transformed to stable iron oxides. This magnetite incorporated arsenic into its structure during precipitation and subsequently adsorbed arsenic. Adsorption to the minerals kept effluent arsenic concentrations $<10 \mu \mathrm{g} \mathrm{L}^{-1}$ for more than $100 \mathrm{PVs}$ despite considerable iron reduction.

Modeling is used to quantify the processes involved the magnetite-based strategy and to scale laboratory results to field environments. Such modelling suggests

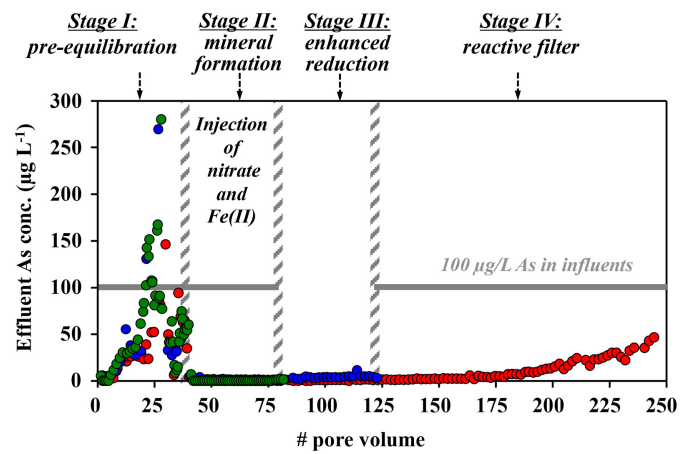

Figure 2. Effluent arsenic concentrations from the columns as a function of PVs. Modified from Sun et al. (2016c).

that the ratio between iron (II) and nitrate in the injectant regulates the formations of magnetite and ferrihydrite, and thus regulates the long-term effectiveness of the strategy. The results from field-scale models favor scenarios that rely on the chromatographic mixing of iron (II) and nitrate after injection.

\section{CONCLUSIONS}

In situ formation of magnetite can be achieved by the microbial oxidation of ferrous iron with nitrate. Magnetite can incorporate arsenic into its structure during formation, forming a stable arsenic sink. Magnetite, once formed, can also immobilize arsenic by surface adsorption, and thus serve as a reactive filter when contaminated groundwater migrates through the treatment zone. These results suggest that a magnetitebased strategy may be a long-term remedial option for arsenic contaminated aquifers.

\section{ACKNOWLEDGEMENTS}

U.S. National Institute of Environmental Health Sciences (grant ES010349 and ES009089).

\section{REFERENCES}

ATSDR, 2015. Summary data for 2015 priority list of hazardous substances.

Prommer, H., Barry, D.A. \& Zheng, C. 2003. MOD-FLOW/ MT3DMS-based reactive multicomponent transport modeling. Groundwater 41(2): 247-257.

Sun, J., Chillrud, S.N., Mailloux, B.J., Stute, M., Singh, R., Dong, H., Lepre, C. J. \& Bostick, B.C. 2016 a. Enhanced and stabilized arsenic retention in microcosms through the microbial oxidation of ferrous iron by nitrate. Chemosphere 144: 1106-1115.

Sun, J., Quicksall, A.N., Chillrud, S.N., Mailloux, B.J. \& Bostick, B.C. 2016b. Arsenic mobilization from sediments in microcosms under sulfate reduction. Chemosphere 153: 254-261.

Sun, J., Chillrud, S.N., Mailloux, B.J. \& Bostick, B.C. 2016c. In situ magnetite formation and long-term arsenic immobilization under advective flow conditions. Environ. Sci. Technol. 50(18): 10162-10171. 


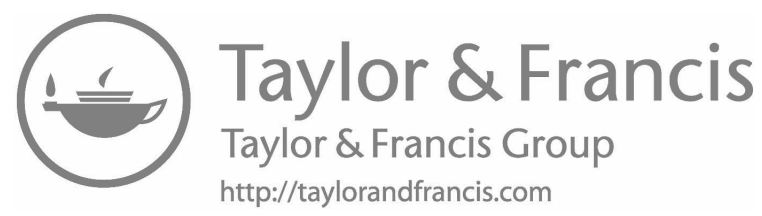

